\title{
The effect of 6-n-propylthiouracil taster status on fruit and vegetable intake and hedonic ratings in a group of Irish children
}

\author{
E. Feeney, S. O'Brien, A. Scannel, A. Markey and E. R. Gibney \\ UCD Centre for Food \& Health, School of Agriculture, Food Science \& Veterinary Medicine, University College Dublin, \\ Belfield, Dublin 4, Republic of Ireland
}

6-n-Propylthiouracil (PROP) is a bitter-tasting compound found in some fruit and vegetables. The ability to taste this compound is determined genetically, controlled in part by alleles of bitter receptor gene TAS2R38 $8^{(1)}$. Individuals vary in their ability to taste this compound and may be categorised into non-tasters (NT) medium tasters (MT) and super tasters (ST) through their rating of a PROPimpregnated disc as described previously ${ }^{(2)}$. Previous studies have shown that vegetable acceptance in young children is lower in PROPtaster groups ${ }^{(3)}$. The aim of the present study was to examine hedonic ratings for twelve common fruits and vegetables, and overall intake in group of twenty-four Irish children aged between 10 and 11 years in relation to their PROP-taster status. Children were asked to rate twelve common fruits and vegetables on a five-point scale. Overall fruit and vegetable intake was assessed through an average 3-day diet history - deemed the most appropriate method of assessment, due the scale of the study and the time allocated.

\begin{tabular}{|c|c|c|c|c|c|c|}
\hline \multirow[t]{3}{*}{ PROP rating range....... } & \multirow{3}{*}{$\frac{1-2}{\text { NTs }(n 0)}$} & \multirow{2}{*}{\multicolumn{2}{|c|}{$\frac{3-7}{\text { MT }(n 11)}$}} & \multirow{2}{*}{\multicolumn{2}{|c|}{$\frac{8-10}{\text { ST }(n 12)}$}} & \multirow{3}{*}{$\begin{array}{l}\text { Significance } \\
\text { of difference }\end{array}$} \\
\hline & & & & & & \\
\hline & & Mean & SD & Mean & SD & \\
\hline Weight (kg) & - & 36.6 & 8.09 & 37.8 & 7.15 & NS \\
\hline Height $(\mathrm{m})$ & - & 1.47 & 0.07 & 1.45 & 0.06 & NS \\
\hline $\operatorname{BMI}\left(\mathrm{kg} / \mathrm{m}^{2}\right)$ & - & 19.9 & 2.77 & 18.8 & 2.44 & NS \\
\hline Fruit and vegetable intake (portions per d) & - & 4.05 & 1.23 & 3.63 & 0.94 & NS \\
\hline Hedonic fruit ratings & - & 1.49 & 0.86 & 1.73 & 0.44 & NS \\
\hline Hedonic vegetable ratings & - & 2.30 & 0.85 & 2.28 & 0.32 & NS \\
\hline
\end{tabular}

There were no significant differences in fruit and vegetable ratings or fruit and vegetable intake in subjects categorised either by PROP rating or by PROP group. This finding was in disagreement with previous studies, but may have been related to: low subject numbers in the study; the fact that subjects were rated by taste and not by genotype; subjects rating the taste of PROP on a narrow 1-10 scale that may have masked differences that would be seen using the wider 'general labelled magnitude scale' ${ }^{(4)}$. The results presented here are from the pilot of a larger on-going study aiming to examine the eating habits and reasons for food choice in Irish children and their parents.

This study is funded by the Food Institutional Research Measure (FIRM), Department of Agriculture and Food, Ireland.

1. Kim UK \& Drayna D (2004) Clin Genet 67, 275-280.

2. Drewnowski A, Henderson SA \& Shore AB (1997) Chem Senses 22, 27-37.

3. Turnbull B \& Matisoo-Smith E (2002) Am J Clin Nutr 76, 1101-1105.

4. Bartoshuk LM, Duffy VB, Fast K, Green BG \& Snyder D (2002) J Food Qual. Prefer. 14, 125-138 